ORIGINAL PROF-2337

\title{
PATIENT SATISFACTION;
}

\author{
OPD services in a Tertiary Care Hospital of Lahore
}

Dr. Fatima Mukhtar, Dr. Aftab Anjum, Dr. Muhammad Aslam Bajwa, Shahzana Shahzad, Shahzeb Hamid, Zahra Masood, Ramsha Mustafa

ABSTRACT... Introduction: Patient satisfaction is a relative phenomenon, which embodies the patients perceived need, his expectations from the health system, and experience of health care. Objective: To determine the level of patient satisfaction towards OPD services with reference to doctor-patient interaction, registration desk, waiting area, and overall health facilities. Study Design: Descriptive cross sectional study. Setting: Tertiary care hospital of Lahore. Study Period: April 2013. Material \& Methods: A sample of 250 patients was selected by employing systematic random sampling technique. The patients were interviewed and data was collected using a pretested questionnaire. Data was analyzed using the statistical package for social sciences (SPSS) version 16.00. Data was presented in figures and tables. It was described using frequencies, percentages and mean. Results: Majority of the patients i.e 232 (94\%) reported being satisfied with the doctor. A vast majority agreed that hospital was clean $233(94 \%)$ and adequately ventilated 224 (90\%). The hospital staff in the waiting area was found to be respectful 220 (89\%) and fair $198(80 \%)$ towards the patients. The patients had no difficulty locating the reception desk of the health facility 235 (95\%). A large proportion of patients i.e.220 (89\%) said they would re-visit the hospital. Conclusions: The patients were highly satisfied with their doctors and were ready to re-visit the hospital. It is recommended that further studies should be conducted to assess patient satisfaction in the secondary and primary care health facilities and efforts should be made to get regular feedback from the patients.

Key words: Patient satisfaction, waiting area, doctor-patient interaction, health facility.

Article Citation

Mukhtar F, Anjum A, Bajwa MA, Shahzad S, Hamid S, Masood Z, Mustafa R. Patient satisfaction; OPD services in a Tertiary Care Hospital of Lahore. Professional Med J 2013;20(6): 973-980.

\section{INTRODUCTION}

Patient satisfaction is a relative phenomenon, which has been around since 1960's but active research on the topic was initiated in late 1970's and early 1980's. This led to the replacement of the idea of 'quantity of life' by a more patient centered concept of 'quality of life $^{1 .}$. Patient satisfaction embodies the patients perceived need, his expectations from the health system, and experience of health care. This multidimensional concept includes both medical and nonmedical aspects of health care ${ }^{2}$. Various theories of patient satisfaction in healthcare have been published. These theories include the expectancy value theory, which proposes patients beliefs, values and prior expectations regarding care to influence patient satisfaction and another is the health care quality theory, which emphasizes that interpersonal process of care plays a paramount role in ensuring patient satisfaction ${ }^{3}$.

The literature review highlights many factors that can affect patient satisfaction. These determinants can be either provider-related or patient-related. Some provider-related factors are physician's proficiency and interpersonal communication skills, behavior of hospital staff, access to care, basic facilities, and infrastructure. Patient-related factors include sociodemographic characteristics of patients, stage of their disease as well as patients' perception of a relationship of trust and feeling of being involved in decisions about their care ${ }^{4,5,6}$.

The modern day patient is more aware and educated, has access to information, and has expectations from the health system. Hence, it is more important today than ever before to address issues related to service delivery in this context ${ }^{\top}$. A patient with positive perceptions has a greater chance of translating it into positive outcomes. Whereas, negative attitudes in the patient and dissatisfaction with health care provided leads to poor compliance and, in extreme cases, patients resort to negative word-of-mouth that 
discourages others from seeking health care from the system $^{8,9}$. Studies have shown that individuals did not visit their local centers of primary health care in Africa even for severe illness due to perceived low quality of healthcare at these centers ${ }^{8}$.

Thus, the reason for laying great emphasis on patient satisfaction is that it is linked to improved compliance of doctors instructions, timely care seeking by the patient, and greater comprehension and retention of information provided by the health care provider ${ }^{2}$. All ensuring a favourable health outcome. Patient satisfaction is also one of the indicators of the quality of care. Its assessment can help in the improvement of health care services and their delivery based on input from the patient ${ }^{10}$.

In Pakistan, some studies have been conducted on patient satisfaction but with focus on specific areas such as the emergency department ${ }^{11}$, day-care surgery $^{12}$ or family medicine sections of the hospital ${ }^{13}$. This survey was conducted to study another important area of services in hospital i.e. Out-Patient Department (OPD) of a hospital. Therefore, a tertiary level care hospital in Lahore was selected for this study with the objectives to determine the level of patient satisfaction towards OPD services with reference to doctor-patient interaction, registration desk, waiting area, and overall health facilities. The results of the study will be useful for hospital administration and managers of health system at different levels to institute meaningful interventions.

\section{METHODOLOGY}

A descriptive cross sectional study was conducted in a tertiary care hospital of Lahore in April 2013. The patients attending OPD services of the hospital comprised the study population. A sample of 250 patients was selected by employing systematic random sampling technique. The previous average OPD attendance was taken as the population size, to calculate the sampling interval or the nth number for a sample of 250 patients. Every nth patient was selected for the interview. This process was continued till the required sample size was completed. The questionnaire developed for data collection contained both open ended and closed ended questions regarding patients socio-demographic history, satisfaction with the doctor, location of registration desk, adequate seats in the waiting area, behavior of the staff and reasons for re-visiting the hospital. It was pilot tested, and after appropriate amendments was used to collect data from the patients. Informed and voluntary consent was taken from the patients after explaining the purpose of the study to them. Data was analyzed using the statistical package for social sciences (SPSS) version 16.00. Data was presented in figures and tables. It was described using frequencies, percentages and mean.

\section{RESULTS}

A total of 250 patients were sampled for the study, but two questionnaires were incomplete, therefore, 248 of them were entered and analyzed. There was almost equal representation of males 127 (51\%) and females 121 (49\%). The mean age of the respondents was 34 \pm 1.58 . The age category of $15-30$ years comprised of $110(44 \%)$ of the respondents, whereas, $18(7 \%)$ were in the age category of $60-75$ years. Of the total respondents, 159 (64\%) were married, 86 (35\%) were never married and 3 (1\%) were divorced/widowed. The education of the patients was categorized into five categories: illiterate, primary, secondary, undergraduate, and graduate. Among them 41 (17\%) were illiterate, 40 (16\%) completed primary school, 74 (30\%) completed secondary school, 78 (31\%) were undergraduates and $15(6 \%)$ were graduates. Majority of the patients were unemployed i.e. 157 (63\%), which among others included housewives and students. Of the working population, 48 (19.4\%) were involved in service, sales and elementary occupations, 10 (4.0\%) were managers, 14 (5.6\%) were professionals (doctors, engineers and highly skilled) and 11 (4.4\%) were involved with agriculture. Very few respondents 
worked as clerks i.e. $7(2.8 \%)$ of them and one respondent belonged to the armed forces $1(0.4 \%)$.

The patients were asked about their satisfaction with the doctor and 232 (94\%) patients reported satisfaction with the doctor (figure 1).

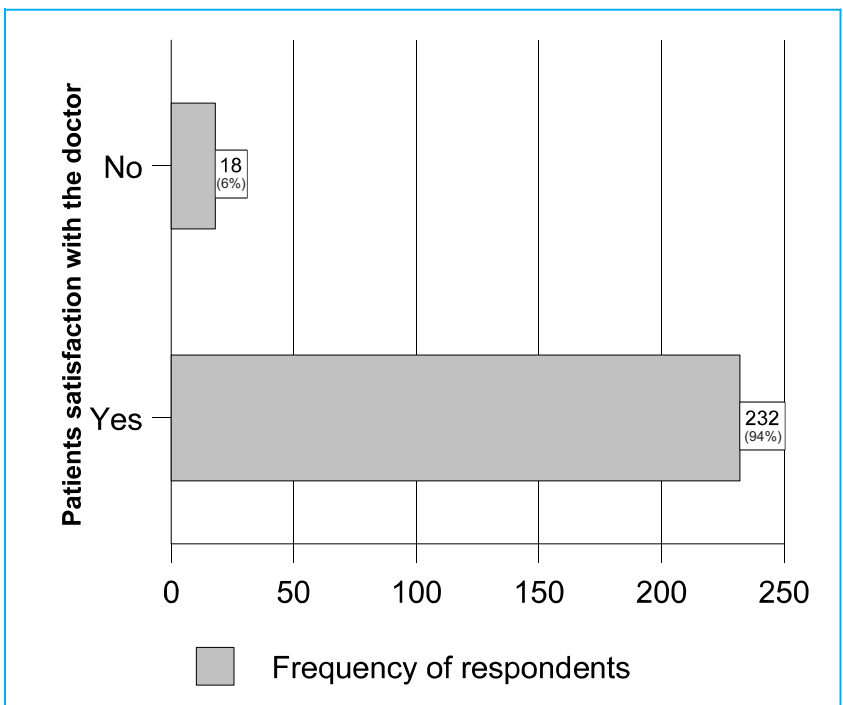

Fig-1. Patients' satisfaction with the doctor

The doctor-patient interaction was explored and analyzed on a 5-point Likert Scale including: $1=$ strongly agree, up to $5=$ strongly disagree. Various aspects of doctor-patient interaction were explored, including respect, privacy, confidentiality, communication skills, informed consent, and addressing the patients' queries (Table l).

The patient's responses towards general aspects of health facility and hospital staff are shown in table no. II. A vast majority agreed that hospital was clean 233 $(94 \%)$ and adequately ventilated $224(90 \%)$. The hospital staff in the waiting area was found to be respectful $220(89 \%)$ and fair $198(80 \%)$ towards the patients. The patients had no difficulty locating the reception desk of the health facility 235 (95\%).

Patients were enquired if they would like to visit the hospital again, to which a large proportion of patients responded positively i.e.220 (89\%) as is highlighted in figure 2.

The patients were asked to identify their reasons for revisiting the hospital facility, and the open-ended responses of the respondents are shown in table no. III.

\section{DISCUSSION}

The present study was an attempt to assess the level of satisfaction of the patients with the various aspects of health care in a tertiary care hospital of Lahore. Patient satisfaction is a multi-dimensional concept, which is not only influenced by physician related factors but also aspects of patient's experience with the health facility ${ }^{13}$. This study looked at the level of satisfaction of patients with their doctor, and it was seen that $94 \%$ of the patients who visited the OPD were satisfied with their doctor. This is a positive response and it is this patient satisfaction, which is in turn responsible for greater compliance with follow up visits and prescribed medicine intake. Contrary results were obtained from a study carried out in Scotland where only $52 \%$ of patients were reasonably satisfied with their doctors ${ }^{14}$.

Patients' views on various aspects of doctor-patient interaction were ascertained. Majority of patients found the doctor to be courteous (98\%), listened attentively to the patients (88\%), gave patients an opportunity to talk about their illness (87\%), provided instructions regarding dose and time of medication $(82 \%)$, advised follow up to the patients $(80 \%)$ and made the patient comfortable during examination (79\%). This is comparable to other international studies which reported that $88-92 \%$ of their patients believed that they were treated with respect and dignity $^{15,16}$. According to a study carried out in Karachi $58.6 \%$ of patients said that consent was taken before examination and $62.4 \%$ of the patients agreed that the doctor maintained privacy ${ }^{17}$. The quality of doctors communication during history taking and discussion 


\begin{tabular}{|c|c|c|c|c|c|c|}
\hline Doctor patient interaction & $\underset{1}{\text { Strongly Agree }}$ & $\begin{array}{c}\text { Agree } \\
2\end{array}$ & $\begin{array}{l}\text { Neutral } \\
3\end{array}$ & $\begin{array}{c}\text { Disagree } \\
4\end{array}$ & $\begin{array}{c}\text { Strongly Disagree } \\
\mathbf{5}\end{array}$ & Mean \\
\hline $\begin{array}{l}\text { Doctor was courteous towards the } \\
\text { patient }\end{array}$ & $94(38 \%)$ & $137(55 \%)$ & $15(6.0 \%)$ & $2(1 \%)$ & $0(0 \%)$ & 1.7 \\
\hline Doctor maintained confidentiality & $66(26.6 \%)$ & $96(39 \%)$ & $63(25 \%)$ & $22(9 \%)$ & $1(0.4 \%)$ & 2.18 \\
\hline $\begin{array}{l}\text { Patient given opportunity to talk } \\
\text { about his illness }\end{array}$ & $93(38 \%)$ & $122(49 \%)$ & $25(10 \%)$ & $8(3 \%)$ & $0(0 \%)$ & 1.78 \\
\hline $\begin{array}{l}\text { Doctor listened to patients problems } \\
\text { attentively }\end{array}$ & $96(39 \%)$ & $122(49 \%)$ & $18(7 \%)$ & $10(4 \%)$ & $2(1 \%)$ & 1.79 \\
\hline $\begin{array}{l}\text { Patient given adequate time during } \\
\text { consultation }\end{array}$ & $66(27 \%)$ & $117(47 \%)$ & $41(16 \%)$ & $22(9 \%)$ & $2(1 \%)$ & 2.1 \\
\hline $\begin{array}{l}\text { Patient given information regarding } \\
\text { his health condition }\end{array}$ & $70(28 \%)$ & $91(37 \%)$ & $48(19 \%)$ & $25(10 \%)$ & $14(6 \%)$ & 2.28 \\
\hline $\begin{array}{l}\text { Doctor addressed patients queries } \\
\text { regarding health condition }\end{array}$ & $71(29 \%)$ & $95(38 \%)$ & $51(20 \%)$ & $27(11 \%)$ & $4(2 \%)$ & 2.19 \\
\hline $\begin{array}{l}\text { Doctor provided instruction regarding } \\
\text { dose and time of medication }\end{array}$ & $102(41 \%)$ & $101(41 \%)$ & $30(12 \%)$ & $13(5 \%)$ & $2(1 \%)$ & 1.84 \\
\hline $\begin{array}{l}\text { Doctor explained side effects of } \\
\text { medication }\end{array}$ & $32(13 \%)$ & $48(19 \%)$ & $49(20 \%)$ & $76(31 \%)$ & $43(17 \%)$ & 3.2 \\
\hline $\begin{array}{l}\text { Doctor explained the reason for } \\
\text { advising investigations }\end{array}$ & $51(21 \%)$ & $54(22 \%)$ & $61(24 \%)$ & $60(24 \%)$ & $22(9 \%)$ & 2.79 \\
\hline $\begin{array}{l}\text { Doctor advised follow up to the } \\
\text { patient }\end{array}$ & $98(40 \%)$ & $100(40 \%)$ & $26(10 \%)$ & $21(9 \%)$ & $3(1 \%)$ & 1.92 \\
\hline $\begin{array}{l}\text { Doctor took informed consent before } \\
\text { examination }\end{array}$ & $49(20 \%)$ & $59(24 \%)$ & $67(27 \%)$ & $61(24 \%)$ & $12(5 \%)$ & 2.71 \\
\hline $\begin{array}{l}\text { Doctor made the patient comfortable } \\
\text { during the examination }\end{array}$ & $69(28 \%)$ & $127(51 \%)$ & 38 (15\%) & $9(4 \%)$ & $5(2 \%)$ & 2.01 \\
\hline $\begin{array}{l}\text { Doctor maintained privacy during } \\
\text { examination }\end{array}$ & $50(20 \%)$ & 83 (33\%) & 60 (24\%) & $36(15 \%)$ & $19(8 \%)$ & 2.56 \\
\hline
\end{tabular}

Table-I. Patients' views towards various aspects of doctor-patient interaction

with the patient has an impact on the health outcome of the patient ${ }^{18}$. We also found that $119(48 \%)$ and 82 $(33 \%)$ patients were of the view that doctors didn't explain the side effects of medication and didn't explain the reason for advising prescription respectively.
Patients were asked about hospital cleanliness, adequate ventilation, location of the registration desk and availability of seats and toilet facility in the waiting area. Majority of the patients were found satisfied with respect to these facilities. In a study conducted by University of North Carolina at Charlotte, patient 


\begin{tabular}{|c|c|c|c|c|}
\hline \multirow{2}{*}{ Variable } & \multicolumn{2}{|c|}{ Yes } & \multicolumn{2}{|c|}{ No } \\
\hline & Frequency & \%age & Frequency & \%age \\
\hline \multicolumn{5}{|l|}{ Reception desk } \\
\hline Reception desk was easy to locate & 235 & 95 & 13 & 05 \\
\hline Faced problem in obtaining OPD ticket & 46 & 18 & 202 & 82 \\
\hline \multicolumn{5}{|l|}{ Waiting area } \\
\hline Waiting area was comfortable & 155 & 63 & 93 & 37 \\
\hline Availability of adequate seating & 155 & 63 & 93 & 37 \\
\hline Availability of drinking water & 172 & 69 & 76 & 31 \\
\hline Staff in waiting area was respectful towards patients & 220 & 89 & 28 & 11 \\
\hline Staff in waiting area treated patients on fair ground & 198 & 80 & 50 & 20 \\
\hline \multicolumn{5}{|l|}{ Overall health facility } \\
\hline Health facility was clean & 233 & 94 & 15 & 06 \\
\hline Health facility was adequately ventilated & 224 & 90 & 24 & 10 \\
\hline
\end{tabular}

satisfaction with waiting time, accessibility of services, and cleanliness of the facility was also high (mean score of 1.70 out of 2) ${ }^{19}$. However, opposing results were found in a study conducted by PIMS Institute, Islamabad. Patient satisfaction with waiting time, accessibility of services, confidentiality and cleanliness of the facility was only $54 \%{ }^{20}$.

According to the protocol followed in the hospital, patients have to obtain a slip from the reception desk before they proceed for their check-up by the doctor.

Predominant number of patients found the reception desk easy to locate. Once in the waiting area the patient interacts with the attendant who is responsible for sending patients inside the doctors room according to their slip numbers. Patients reported being treated fairly and respectfully by the staff in the waiting area.

Such issues involving the attitude of hospital staff with

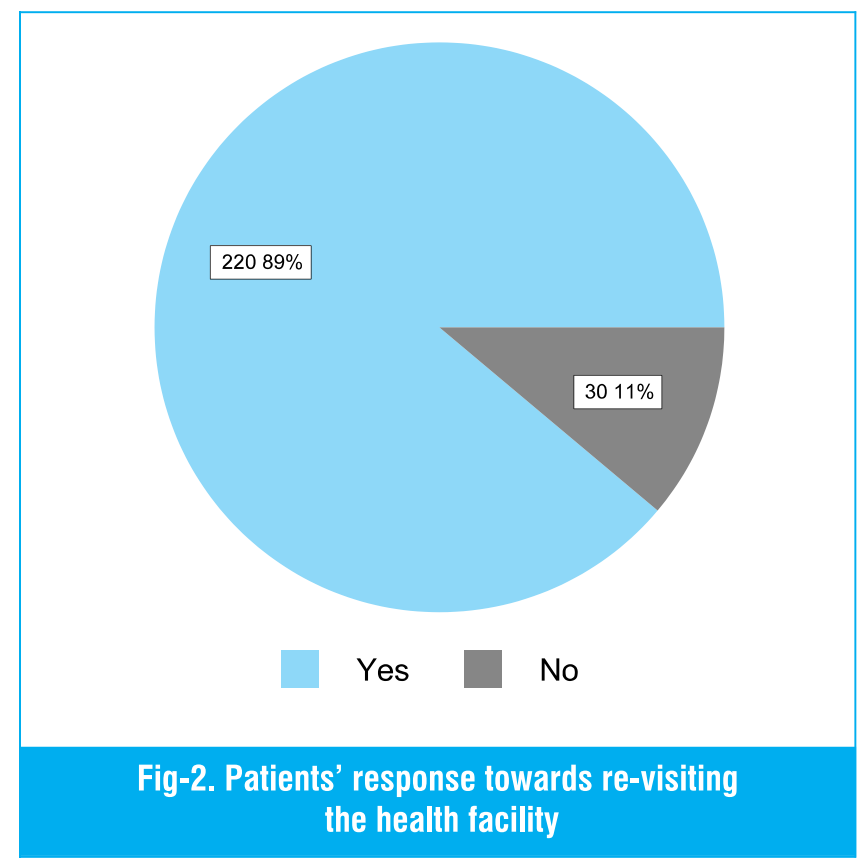

patients can greatly influence the reputation of a hospital and is an important factor towards patient 
satisfaction. Similar results were obtained in the study conducted in Rawalpindi, Pakistan where according to $92.3 \%$ of patents, registration and documentation at the hospital reception was convenient and $96 \%$ were satisfied with reception staff attitude ${ }^{21}$.

A large proportion of patients (89\%) were found to be satisfied and willing to re-visit the hospital. This was found to be a very encouraging response and portrays a high satisfaction of the patients with the hospital. Patient satisfaction is an indirect or a proxy indicator of the quality of doctor or hospital performance. This high satisfaction found by the study could be attributed to the hospital being a private hospital $^{22}$.

\begin{tabular}{|c|}
\hline Reasons for re-visiting the hospital \\
\hline "overall environment and doctors behaviour was good" \\
\hline $\begin{array}{l}\text { "Very affordable fee, efficient doctors and facility near my } \\
\text { house" }\end{array}$ \\
\hline "trust in doctors, satisfied with the treatment" \\
\hline "treatment affordable, hospital clean and ventilated" \\
\hline "I am regular patient, satisfied with the doctor" \\
\hline "polite behaviour of the doctor" \\
\hline "near my home" \\
\hline "near to my residence, well reputed doctors \\
\hline "close to house, clean and doctors are helpful" \\
\hline "health facility up to date" \\
\hline "the medicines prescribed to me were efefctive" \\
\hline "hospital is well organized and competent doctors" \\
\hline "doctors gave their full attention" \\
\hline "have always been coming here" \\
\hline "enough time given and good behaviour of staff" \\
\hline "doctors are kind and cooperative" \\
\hline $\begin{array}{l}\text { Table-III. Reasons identified by patients for } \\
\text { re-visiting the hospital }\end{array}$ \\
\hline
\end{tabular}

\section{CONCLUSIONS}

The patients were highly satisfied with their doctors. They found them courteous and attentive towards the patients. The health facility was clean and adequately ventilated. Majority of the patients were ready to re-visit the hospital.

\section{RECOMMENDATIONS}

It is recommended that further studies should be conducted to assess patient satisfaction in the secondary and primary care health facilities.

Efforts should be made to get regular feedback from the patients.

\section{Copyright@ 07 0ct, 2013.}

\section{REFERENCES}

1. Ekram S, Rahman F. The concept of patient satisfaction as it relates to contemporary health care. TAJ 2006; 19(1): TAJ: ISSN 1019-8555.

2. Silva AD. A framework for ensuring responsiveness. GPE discussion paper series: No.32. World Health Organization.

3. Gill L, White L. A critical review of patient satisfaction. Leadership in Health Services 2009; 22(1): 8-19.

4. Sofaer S, Crofton C, Goldstein E, Hoy E, Crabb J. What do consumers want to know about the quality of care in hospitals? Health Serve Res 2005; 40; 2018-36.

5. Renzi C, Abeni D, Picardi A, Agostini E, Melchi CF, Pasquini P, Puddu P, Braga M. Factors associated with patient satisfaction with care among dermatological outpatients. $\mathrm{Br} \mathrm{J}$ Dermatol 2001; 145(4):617-23.

6. Schoenfelder T, Klewer J, Kugler J. Determinants of patient satisfaction: a study among $\mathbf{3 9}$ hospitals in an in-patient setting in Germany. International Journal for quality in Health carte 2011; 23(5):503-9.

7. Bamidele AR, Hoque ME, Van der Heever H. Primary satisfaction with the quality of care in a primary health care setting in Botswana. S Afr Fam Pract 2011;53(2): 170-5 
8. Khattak A, Alvi MI, Yousaf MA, Shah SZ, Turial D, Akhter S. Patient Satisfaction - A Comparison between Public \& Private Hospitals of Peshawar. Int J Collab Res Inter Medi Public Health 2012; 4(5):713.

9. Debono D, Travaglia J. Complaints and patient satisfaction: a comprehensive review of the literature. Centre for Clinical Governance Research, University of New South Wales, Sydney, Australia. National Library of Australia. 2009.

10. Qidwai W, Ali SS, Baqir M, Ayub S. Patients expectations from an emergency medical service. $J$ Ayub Med Coll Abbottabad 2005, 17(3): 3-6.

11. Ahmad M, Zafar A, Griffin S, Ahmad S, Orakzai N, Fayyaz F. An audit of patients' satisfaction after adult day-case surgery at Ayub Teaching Hospital, Abbottabad. J Ayub Med Coll Abbottabad 2005, 17(1):22-25.

12. Qidwai W, Dhanani RH, Khan FM: Implications for the practice of a patient expectation and satisfaction survey at a teaching hospital in Karachi, Pakistan. J Pak Med Assoc 2003, 53(3):122-5.

13. Naseer M, Zahidie A, Shaikh BT. Determinants of patient's satisfaction with health care system in Pakistan: a critical review. Pak J Public Health 2012;2(2):56-61.

14. Richardson IM, Howie IG, Durno D, Gill G, Fordyee ID. Study of General Practitioner Consultations in North-East Scotland. J.R.Coll Gen Pract 1973 Feb;23. British Journal of General Practitioners.
15. Cleary PD, Edgman-Levitan S, Roberts M, Moloney TW, McMullen W, Walker JD, et al. Patients evaluate their hospital care: a national survey. Health Affairs 1991; 10: 25467.

16. Gouveia GC, Souza WV, Luna CF, Souza-Junior PR, Szwarcwald CL. Health care users' satisfaction in Brazil. Cad Saude Publica 2005; 21:109-18.

17. Jawaid M, Ahmed N, Alam SN, Rizvi BH, Razzak HA. Patients experiences and satisfaction from surgical outpatient department of a tertiary care teaching hospital. Pak J Med Sci 2009;25(3):439-42.

18. Stewart MA. Effective physician-patient communication and health outcomes: a review. CMAJ 1995; 152(9): 1423-33.

19. Harutyunyan T, Demirchyan A, Thompson ME, Petrosyan V. Patient satisfaction with primary care in Armenia: good rating of bad services? Health Services Management Research 2010;23(1):12-7.

20. Javed A. Patient satisfaction towards out patient department services in Pakistan Institute of Medical Sciences, Islamabad. (Masters Thesis). Mahidol University, 2005.

21. Khan OA, Iqbal M, Waseem AG. Patients' Experience and Satisfaction with Healthcare at Pakistan Railways Hospital Rawalpindi. Ann Pak Inst Med Sci 2012; 8(2): 122-4.

22. Tengilimoglu D, Kisa D, Dziegielewski SF. Patient satisfaction in Turkey: differences between public and private hospitals. J Community Health 1999; 24(1): 73-91. 


\section{AUTHOR(S):}

\section{DR. FATIMA MUKHTAR}

MBBS, DTM\&H, MPhil, PhD (Public health) student

Associate Professor,

Department of Community Medicine,

Lahore Medical \& Dental College.

2. DR. AFTAB ANJUM

MBBS, MCPS, FCPS

Associate Professor,

Department of Community Medicine,

Lahore Medical \& Dental College.

3. DR. MUHAMMAD ASLAM BAJWA

MBBS, FCPS

Assistant Professor,

Department of Community Medicine,

Lahore Medical \& Dental College.

\section{Shahzana Shahzad}

4th Year Student

5. Shahzeb Hamid

4th Year Student

6. Zahra Masood

4th Year Student

7. Ramsha Mustafa

4th Year Student

Correspondence Address:

Dr. Fatima Mukhtar

7 Aziz Bhatti Road,

Lahore Cantt, Lahore.

fatimamukhtar@doctor.com
Article received on: $29 / 08 / 2013$ Accepted for Publication: 07/10/2013 Received after proof reading: 03/12/2013

\section{PREVIOUS RELATED STUDIES}

Naveed Jabbar, Lamees Mahmood Malik, Shahid Hameed, Aftab Ahmed CH., PATIENT SATISFACTION AND MERGING OF SMALL HOSPITAL (Original) Prof Med Jour 18(3) 525-529 Jul, Aug, Sep 2011.

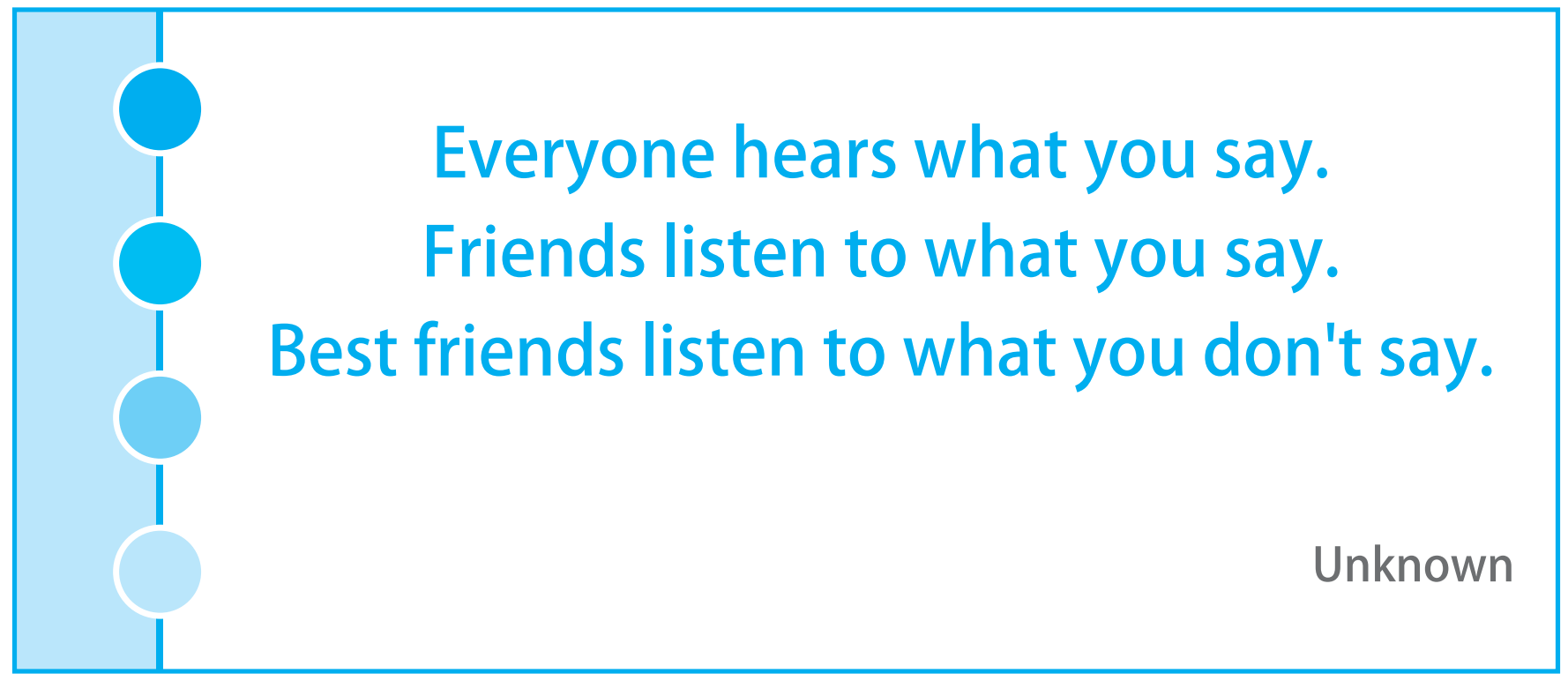

